\title{
Suplementos Energéticos para Recria de Novilhas de Corte em Pastagens Anuais. Análise Econômica ${ }^{1}$
}

\author{
Davi Teixeira dos Santos ${ }^{2}$, Marta Gomes da Rocha ${ }^{3}$, Teresa Cristina Moraes Genro ${ }^{4}$, Fernando \\ Luiz Ferreira de Quadros ${ }^{3}$, Fabiana Kellermann de Freitas ${ }^{5}$, Juliano Roman ${ }^{6}$, Fabio Pereira Neves ${ }^{7}$
}

RESUMO - Foi realizada uma avaliação econômica de dois experimentos com sistemas intensivos de alimentação para recria de novilhas de corte desmamadas aos 60-90 dias. No experimento 1, as novilhas permaneceram em pastagem de milheto, exclusivamente sob pastejo $\left(\mathrm{PAST}_{1}\right)$; suplementadas com grão de milho moído $\left(\mathrm{PAST}_{1} / \mathrm{M}\right)$ ou suplementadas com polpa cítrica peletizada e moída $\left(\mathrm{PAST}_{1} / \mathrm{P}\right)$. No experimento 2, foram mantidas em pastagem de aveia preta e azevém, sem suplementação ( $\mathrm{PAST}_{2}$; ; suplementadas com grão de milho moído ( $\left.\mathrm{PAST}_{2} / \mathrm{M}\right)$ ou suplementadas com casca de soja $\left(\mathrm{PAST}_{2} / \mathrm{C}\right)$. A partir dos resultados de produção animal por hectare e da composição dos custos, realizou-se uma avaliação da resposta financeira direta dos sistemas de alimentação estudados. Com base no peso vivo médio das novilhas aos doze meses de idade, foi apresentada uma análise bioeconômica das tecnologias empregadas. No experimento 1, a suplementação com grão de milho apresentou prejuízo financeiro, enquanto os demais sistemas praticamente cobriram os custos, sem margem bruta excedente. No experimento 2, o sistema que utilizou o grão de milho como suplemento cobriu somente os custos, e o uso exclusivo da pastagem e a suplementação com casca de soja proporcionaram valores satisfatórios de margem bruta por hectare. O aumento da taxa de natalidade de 50 para $80 \%$ ou a redução da idade das novilhas ao primeiro acasalamento de três para dois anos poderia reduzir, respectivamente, em 62 e $23 \%$ o número de fêmeas improdutivas no rebanho para cada 100 vacas prenhas. Realizadas conjuntamente, estas práticas apresentam potencialidade para reduzir este número de animais em $74 \%$.

Palavras-chave: custo total, desmame precoce (60-90 dias), margem bruta, sistemas de acasalamento

\section{Energy Supplements for Beef Heifers Rearing at Annual Pastures. Economic Analysis}

ABSTRACT - An economic evaluation was accomplished of two experiments with intensive feeding systems for rearing of beef heifers weaned with 60-90 days. In experiment 1, the heifers reared in Pearl Millet pasture, exclusively under grazing $\left(\mathrm{PAST}_{1}\right)$; supplemented with milled corn grain $\left(\mathrm{PAST}_{1} / \mathrm{C}\right)$ or supplemented with pellet citric pulp $\left(\mathrm{PAST}_{1} / \mathrm{P}\right)$. In experiment 2 , the heifers were reared in Oat plus Italian Ryegrass pasture without supplementation to the animals $\left(\mathrm{PAST}_{2}\right) ;$ supplemented with milled corn grain $\left(\mathrm{PAST}_{2} / \mathrm{C}\right)$ or supplemented with soy hull $\left(\mathrm{PAST}_{2} / \mathrm{H}\right)$. With the results of animal production per hectare and composition of the costs was realized an evaluation of the direct financial response of the studied feeding systems. Based on the live weight of the heifers at twelve months of age a bioeconomic analysis of the employed technologies was presented. In experiment 1, the milled corn grain supplemented presented financial loss, while other systems just only covered costs, without surplus gross margin. In experiment 2, the corn grain system covered only costs, and the exclusive use of the pasture and the soy hull supplementation provided satisfactory values of gross margin for hectare. The increase of birth rate from 50 to $80 \%$ or the reduction of the age at first mating of the heifers from three to two years could reduce, respectively, in 62 and $23 \%$ the number of unproductive females in the herd for each 100 pregnant cows. These practices present potentiality to reduce this number of animals in $74 \%$, when accomplished jointly.

Key Words: total cost, early weaning (60-90 days), gross margin, mating systems

\section{Introdução}

A pecuária de corte brasileira passa por um momento de extrema euforia com a atividade de cria, em um movimento de migração ocorrido desde 1997.
Como conseqüência, o aumento no número de animais em fase de recria também foi observado, notadamente na população de fêmeas. Atualmente, o rebanho produtor de carne bovina do país é composto por $48,2 \%$ dos animais em recria, $40,4 \%$ na fase de

\footnotetext{
1 Parte da dissertação de mestrado do primeiro autor, PPGZ-UFSM, Santa Maria, RS.

2 Zoot., aluno do PPGZ-UFSM, Santa Maria, RS. Bolsista CAPES. E.mail: daviteixeira@hotmail.com

${ }^{3}$ Eng. Agr., Dr., Prof. Adjunto do Departamento de Zootecnia, UFSM. E.mail: tata@pro.via-rs.com.br

4 Zoot. Drà., Pesquisadora EMBRAPA Pecuária Sul, Bagé, RS. E.mail: cristina@ccpsul.embrapa.br

5 Eng. Agr., aluna do PPGZ-Zootecnia, UFSM, RS. E.mail: setorforrageiras@bol.com.br

${ }^{6}$ Aluno do curso de Graduação em Agronomia, UFSM, RS.

${ }^{7}$ Aluno do curso de Graduação em Agronomia, bolsista FAPERGS, UFSM, RS
} 
cria e 11,4\% em fase de terminação (Zervoudakis et al., 2002). Além de abrigar elevado contingente populacional, a recria retém os bovinos por longo período, chegando a representar, no caso das fêmeas, $66 \%$ do tempo necessário para uma novilha parir seu primeiro bezerro. Estes dois fatores contribuem negativamente para a eficiência do processo produtivo como um todo.

Maior taxa de natalidade e menores idade ao primeiro acasalamento das fêmeas e idade ao abate dos machos reduzem o número de categorias improdutivas (vacas falhadas, novilhas de reposição, novilhos em mantença ou com baixas taxas de ganho) a serem mantidas no rebanho para cada 100 bezerros produzidos anualmente (Mielitz Netto, 1979).

Desses índices, no entanto, apenas uma redução na população de bois de 3-4 anos foi registrada pela estatística de composição do rebanho brasileiro (Anualpec, 2002). Nos últimos cinco anos, o crescimento verificado nas fases de cria e recria foi decorrente de maior retenção de vacas no rebanho, o que gerou ainda aumento na produção de bezerros. Isto permite predizer que a busca de alternativas biológica e economicamente eficientes na recria desses animais estará novamente em evidência nos próximos anos.

No Brasil, a exploração pecuária está alicerçada fundamentalmente no uso de pastagens e é compreensível que assim permaneça. No Rio Grande do Sul, por exemplo, a criação de gado de corte ocupa aproximadamente $56 \%$ da área do estado. Sua contribuição em termos monetários, no entanto, é de apenas $6,29 \%$ da receita global, valor que já correspondeu a mais de $60 \%$ em épocas passadas (Pötter, 1997). A principal explicação para que os sistemas criatórios sejam tradicionalmente extensivos e de baixa eficiência reside no fato de que, na maioria das situações, a forragem disponível não contém todos os nutrientes essenciais para a proporção adequada, de modo a atender integralmente as exigências dos animais em pastejo (Hogdson, 1990).

Em um sistema tradicional representado por animais mantidos exclusivamente em pastagem nativa, as fêmeas permanecem improdutivas no campo por três anos, seu desempenho reprodutivo subsequiente é prejudicado, a taxa de natalidade não ultrapassa $50 \%$ e os resultados de repetição de prenhez oscilam entre 18 e 20\% (Cachapuz, 1995). Um sistema intensivo consiste na combinação e utilização de diversas tecnologias, visando o aumento da produtividade nas diferentes fases do processo produtivo como um todo ou em cada uma delas isoladamente. Está baseado na utilização de pastagem natural, melhorada ou cultivada, empregando também grãos e subprodutos da indústria (Salomoni, 1987). Para ser viável economicamente, no entanto, um sistema intensivo deve apresentar taxa de natalidade superior a $75 \%$ (Salles et al., 1987). Comparando um sistema tradicional com desmame dos animais aos 90 dias de idade, Grawunder (1988) estimou que esta técnica teria potencialidade para elevar a taxa de natalidade dos históricos de $50 \%$ para valores entre 70 e $80 \%$.

A pecuária de corte dispõe de poucos trabalhos relativos a sua economicidade, contrastando com a abundância de dados que dizem respeito à área de geração de tecnologias (Pötter et al., 2000). Neste estudo, objetivou-se fazer uma avaliação econômica de dois experimentos envolvendo sistemas intensivos de alimentação para recria de novilhas de corte desmamadas aos 60-90 dias, a partir da resposta financeira dos sistemas estudados e do seu impacto sobre o sistema criatório como um todo.

\section{Material e Métodos}

Os experimentos foram desenvolvidos em área do Departamento de Zootecnia da Universidade Federal de Santa Maria, RS, localizada na Depressão Central do estado, com altitude de $95 \mathrm{~m}$, latitude $29^{\circ}$ $43^{\prime}$ sul e longitude $53^{\circ} 42^{\prime}$ oeste. O clima da região é Cfa (subtropical úmido) conforme classificação de Köppen (Moreno, 1961). O experimento 1 foi realizado de 16/02 a 21/04/2001 e o experimento 2 de 13/ 07 a 09/10 do mesmo ano.

A área experimental total (5,8 ha) foi constituída de seis subdivisões de 0,7 ha (unidades experimentais) mais uma área de 1,6 ha para alojar animais reguladores da massa de forragem. Foram utilizadas novilhas mestiças, oriundas de cruzamentos entre as raças Charolês, Nelore, Hereford e Angus, com idade e peso médios iniciais de 100 dias e $95,5 \mathrm{~kg}$, respectivamente. Os animais foram agrupados em três lotes uniformes conforme o tipo racial, sendo os lotes distribuídos ao acaso nos tratamentos em ambos os experimentos, descritos a seguir:

As novilhas desmamadas com idade entre 60 e 90 dias foram mantidas sob pastejo contínuo, dos três aos cinco meses de idade, em pastagem de milheto (Pennisetum americanum (L.) Leeke) com lotação variável (Mott \& Lucas, 1952), recebendo ou não

R. Bras. Zootec., v.33, n.6, p.2359-2368, 2004 (Supl. 3) 
suplementos energéticos. A pastagem foi implantada no dia $03 / 01 / 2001$, pelo método convencional, utilizando-se $200 \mathrm{~kg} / \mathrm{ha}$ de adubo da fórmula 05-20-20 e $35 \mathrm{~kg} / \mathrm{ha}$ de sementes de milheto. A adubação de cobertura foi de $150 \mathrm{~kg} / \mathrm{ha}$ de nitrogênio (N) na forma de uréia, parcelados em duas aplicações. Os animais iniciaram o período de pastejo em 16/02, distribuídos nos tratamentos: $\mathrm{PAST}_{1}$ - pastagem de milheto, sem suplementação aos animais; $\mathrm{PAST}_{1} / \mathrm{M}$ - pastagem de milheto + suplementação com grão de milho moído; $\mathrm{PAST}_{1} / \mathrm{P}$ - pastagem de milheto + suplementação com polpa cítrica peletizada e moída. O teor de proteína bruta (PB) dos suplementos utilizados nesta etapa foi analisado previamente ao experimento e corrigido com uréia para $12 \%$ PB. Os suplementos foram fornecidos diariamente às $8 \mathrm{~h} 30$, a $0,9 \%$ do peso vivo (PV) dos animais, com base na matéria seca (MS). A quantidade de suplemento oferecida foi regulada semanalmente conforme o ajuste da carga animal. Foram utilizadas quatro novilhas testes por unidade experimental e um número variável de animais reguladores visando conservar a massa de forragem (MF) entre 1.800 e $2.000 \mathrm{~kg} / \mathrm{ha}$ de MS e oferta de forragem de $10 \%$ do PV dos animais. Os animais foram pesados nos dias 16/02, 10/03, 30/03 e 21/04. As pesagens inicial e final foram precedidas por jejum de 12 horas. O manejo sanitário constou de duas aplicações de ivermectina em 14/02 e 30/03.

Após o encerramento do experimento 1 e durante a fase de estabelecimento da pastagem de inverno, todas as novilhas foram mantidas em uma área de pastagem nativa invadida por capim Annoni (Eragrostis planna). Durante este período (82 dias), os animais apresentaram perda de peso de $-0,225 \mathrm{~kg} / \mathrm{dia}$.

No segundo experimento, as novilhas permaneceram, dos oito aos onze meses de idade, sob pastejo contínuo em pastagem de aveia preta (Avena strigosa Schreb) e azevém (Lolium multiflorum Lam) com lotação variável. A pastagem foi implantada pelo método de semeadura direta em 11/05/2001, com 300 $\mathrm{kg} / \mathrm{ha}$ de adubo da fórmula $05-20-20,80 \mathrm{~kg} / \mathrm{ha}$ de sementes de aveia preta e $45 \mathrm{~kg} / \mathrm{ha}$ de sementes de azevém. Em cobertura foram aplicados $150 \mathrm{~kg} / \mathrm{ha}$ de $\mathrm{N}$ na forma de uréia, parcelados em três aplicações. No dia $13 / 07$, as novilhas ingressaram na pastagem com peso médio de $110 \mathrm{~kg}$ distribuídas nos tratamentos: $\mathrm{PAST}_{2}$ - pastagem de aveia preta e azevém, sem suplementação aos animais; $\mathrm{PAST}_{2} / \mathrm{M}$ - pastagem de aveia preta e azevém + suplementação com grão de milho moído; $\mathrm{PAST}_{2} / \mathrm{C}$ - pastagem de aveia preta e azevém + suplementação com casca do grão de soja. Os suplementos foram fornecidos diariamente às 14:00h, ao nível de 0,9\% do PV dos animais, com base na MS. A quantidade de suplemento oferecida foi regulada semanalmente conforme a carga animal, ajustada a uma oferta de forragem de $10 \%$ do PV. Foram utilizadas três novilhas testes por unidade experimental, além de número variável de animais reguladores para conservar a MF entre $1.300 \mathrm{e}$ $1.500 \mathrm{~kg} / \mathrm{ha}$ de MS. As pesagens dos animais foram realizadas nas datas 13/07, 11/08, 07/09 e 09/10, todas precedidas por jejum de seis horas. $\mathrm{O}$ manejo sanitário dos animais constou de duas aplicações de produto ivermectina, em 10/07 e 18/09.

As variáveis de produção animal avaliadas em ambos os experimentos foram: ganho de peso diário médio (GDM), carga animal média (CAM) e ganho de peso vivo por área (GPA). Os dados referentes a estes parâmetros foram submetidos à análise de variância e teste $\mathrm{F}$ a $5 \%$ e, quando detectadas diferenças, as médias foram comparadas pelo teste de Tukey ao mesmo nível de significância. Com base nos resultados de ordem biológica, realizou-se uma apreciação econômica dos sistemas alimentares estudados por experimento, considerando custo total (CT), receita bruta $(\mathrm{RB})$, margem bruta $(\mathrm{MB})$ e retorno financeiro direto (RFD) por tratamento. A planilha de custos foi elaborada segundo o modelo apresentado por Pötter et al. (1998), utilizando-se o Microsoft Excel versão 5.0.

O levantamento de preços dos tratores, implementos agrícolas, sementes, fertilizantes, suplementos, salário mínimo rural e demais insumos foram obtidos em consultas a empresas da região de Santa Maria - RS, durante o mês de janeiro de 2003. O valor do beneficiamento da ração foi correspondente à taxa cobrada por cooperativas agrícolas da região ( $10 \%$ sobre o valor dos ingredientes). O custo da mãode-obra foi estabelecido a partir do salário mínimo rural do estado, somado aos encargos sociais, considerandose um total de 220 horas mensais de trabalho. Para os custos dos tratores, foram somados os gastos de depreciação, conservação, combustíveis, lubrificantes e mão-de-obra e, para os implementos, foram computados os custos de depreciação e conservação.

Para determinação da quantidade de vermífugo fornecida em cada tratamento, a carga animal média foi dividida pelo peso médio dos animais testes. Obteve-se, dessa forma, a taxa de lotação média, foi multiplicada pelo número de aplicações e pela quan-

R. Bras. Zootec., v.33, n.6, p.2359-2368, 2004 (Supl. 3) 
tidade de produto por animal. O sal comum foi fornecido à vontade e seu consumo médio estimado em 30 e 50 gramas/animal/dia, respectivamente, para os experimentos 1 e 2 . O total de sal fornecido foi calculado pela multiplicação da lotação média pelo consumo estimado e pelo período total de permanência dos animais na pastagem. As quantidades de suplemento foram calculadas multiplicando-se a carga animal média pelo nível de suplementação (1\% do PV com base no suplemento oferecido) e pelo período total de fornecimento do suplemento. A quantidade de uréia adicionada aos suplementos no experimento 1 foi de 7 e 16 gramas/animal/dia, respectivamente, para animais suplementados com grão de milho e polpa cítrica. Esses valores foram multiplicados pelo período total de suplementação do experimento e pela lotação média para estimativa da quantidade total de uréia na ração. Os custos referentes à uréia utilizada na ração e à moagem dos suplementos foram inseridos no item 'suplemento'. A necessidade de cochos foi estimada em quatro metros lineares por hectare nas dimensões de $0,3 \mathrm{~m}$ de altura x 0,6 m de largura.

Posteriormente à análise individual de cada experimento, as novilhas foram reagrupadas conforme o recebimento ou não de suplementação nos experimentos 1 e 2 . A partir dos valores de peso vivo das novilhas ao completar um ano de idade, foram feitas estimativas de GDM necessários para o acasalamento aos 14,18 ou 24 meses, considerando-se $420 \mathrm{~kg}$ como peso de vaca adulta e $65 \%$ deste valor $(273 \mathrm{~kg})$, como peso-alvo para o início do acasalamento. De posse dessas informações foi realizada uma apreciação do impacto das alterações de ordem biológica proporcionadas pelos sistemas estudados sobre alguns aspectos ligados à economicidade do sistema de produção como um todo. Para esta análise, foi utilizado o modelo de composição do rebanho de cria proposto por Beretta et al. (2001).

Tabela 1 - Custos de implantação e manutenção da pastagem de milheto (custo básico) e custos referentes à suplementação com grão de milho ou polpa cítrica (custo adicional) para recria de novilhas de corte. Valores expressos em kg PV de novilha - experimento 1

Table 1 - Implantation and maintenance costs of pearl millet pasture (basic cost) and costs with corn grain or citric pulp supplementation (additional cost) to beef heifers growing. Values explicit in $\mathrm{kg} L W$ of heifer - experiment 1

\begin{tabular}{|c|c|c|c|c|}
\hline \multirow[t]{2}{*}{$\begin{array}{l}\text { Componente do custo } \\
\text { Cost component }\end{array}$} & \multirow[t]{2}{*}{$\begin{array}{l}\text { Quantidade/ha } \\
\text { Quantity/ha }\end{array}$} & \multicolumn{3}{|c|}{$\begin{array}{c}\text { Tratamento } \\
\text { Treatment }\end{array}$} \\
\hline & & $\begin{array}{l}\mathrm{PAST}_{1} \\
P_{P A S T}\end{array}$ & $\begin{array}{c}\mathrm{PAST}_{1} / \mathrm{M} \\
P A S T_{1} / C \\
\end{array}$ & $\begin{array}{r}\mathrm{PAST}_{1} / \mathrm{P} \\
P_{1 S T_{1}} / \mathrm{P} \\
\end{array}$ \\
\hline Preparo do solo (Soil cultivation) & $2,91 \mathrm{~h}$ & 34,66 & 34,66 & 34,66 \\
\hline Semente de milheto (Pearl millet seeds) & $35 \mathrm{~kg}$ & 10,29 & 10,29 & 10,29 \\
\hline Adubo (05-20-20) (Fertilizer [05-20-20]) & $200 \mathrm{~kg}$ & 76,47 & 76,47 & 76,47 \\
\hline Transporte de insumos (Transport) & $0,3 \mathrm{~h}$ & 2,57 & 2,57 & 2,57 \\
\hline Semeadura/adubação (Seeding/fertilization) & $0,61 \mathrm{~h}$ & 4,34 & 4,34 & 4,34 \\
\hline Uréia (45-00-00) (Urea [45-00-00]) & $333 \mathrm{~kg}$ & 129,28 & 129,28 & 129,28 \\
\hline Transporte de uréia (Urea transport) & $0,5 \mathrm{~h}$ & 5,14 & 5,14 & 5,14 \\
\hline Aplicação de uréia (Urea aplication) & $0,4 \mathrm{~h}$ & 4,34 & 4,34 & 4,34 \\
\hline Arrendamento (Lease) & 0,5 ano & 15,16 & 15,16 & 15,16 \\
\hline Custo básico (Basic cost) & $\mathrm{kgPV}$ & 282,27 & 282,27 & 282,27 \\
\hline Sal comum (Salt) & $\mathrm{kg}$ & 4,39 & 5,20 & 5,0 \\
\hline Monensina sódica (Sodic monensin) & $\mathrm{kg}$ & 10,65 & 12,61 & 12,12 \\
\hline Vermífugo (Vermifuge) & $\mathrm{L}$ & 13,41 & 15,88 & 15,26 \\
\hline Mão-de-obra (Labor) & $\mathrm{h}$ & 3,80 & 26,62 & 26,62 \\
\hline Suplemento (Supplement) & $\mathrm{kg}$ & & 252,60 & 162,05 \\
\hline Transporte (Transport) & $\mathrm{h}$ & & 27,77 & 27,77 \\
\hline Cocho (Trough) & $\mathrm{m}$ & & 4,94 & 4,94 \\
\hline Custo adicional (Additional cost) & $\mathrm{kg}$ PV & 32,25 & 345,62 & 253,76 \\
\hline Custo total (Total cost) & $\mathrm{kgPV}$ & 314,53 & 627,89 & 536,03 \\
\hline
\end{tabular}

R. Bras. Zootec., v.33, n.6, p.2359-2368, 2004 (Supl. 3) 
Tabela 2 - Custos de implantação e manutenção da pastagem de aveia preta e azevém (custo básico) e custos referentes à suplementação com grão de milho ou casca de soja (custo adicional) para recria de novilhas de corte. Valores expressos em kg PV de novilha - experimento 2

Table 2 - Implantation and maintenance costs of the Oat and Annual Ryegrass pasture (basic cost) and costs with corn grain or soy hull supplementation (additional cost) for beef heifers rearing. Values explicit in $\mathrm{kg} L W$ of heifer - experiment 2

\begin{tabular}{|c|c|c|c|c|}
\hline \multirow[t]{2}{*}{$\begin{array}{l}\text { Componente do custo } \\
\text { Cost component }\end{array}$} & \multirow[t]{2}{*}{$\begin{array}{l}\text { Quantidade/ha } \\
\text { Quantity/ha }\end{array}$} & \multicolumn{3}{|c|}{$\begin{array}{c}\text { Tratamento } \\
\text { Treatment }\end{array}$} \\
\hline & & $\begin{array}{l}\text { PAST }_{1} \\
\text { PAST }_{1}\end{array}$ & $\begin{array}{c}\mathrm{PAST}_{1} / \mathrm{M} \\
P A S T_{1} / C\end{array}$ & $\begin{array}{r}\mathrm{PAST}_{1} / \mathrm{P} \\
P_{A S T} / P\end{array}$ \\
\hline Herbicida (Herbicid) & $2,0 \mathrm{~L}$ & 15,18 & 15,18 & 15,18 \\
\hline Aplicação de herbicida (Herbicid application) & $0,1 \mathrm{~h}$ & 1,64 & 1,64 & 1,64 \\
\hline Semente de aveia preta (Oat seeds) & $80 \mathrm{~kg}$ & 25,88 & 25,88 & 25,88 \\
\hline Semente de azevém (Ryegrass seeds) & $45 \mathrm{~kg}$ & 25,15 & 25,15 & 25,15 \\
\hline Adubo (05-20-20) (Fertilizer 05-20-20) & $300 \mathrm{~kg}$ & 114,71 & 114,71 & 114,71 \\
\hline Transporte de insumos (Transport) & $0,3 \mathrm{~h}$ & 2,57 & 2,57 & 2,57 \\
\hline Semeadura/adubação (Seeding/fertilization) & $0,7 \mathrm{~h}$ & 17,04 & 17,04 & 17,04 \\
\hline Uréia (45-00-00) (Urea 45-00-00) & $333 \mathrm{~kg}$ & 129,28 & 129,28 & 129,28 \\
\hline Transporte de uréia (Urea transport) & $0,75 \mathrm{~h}$ & 2,57 & 2,57 & 2,57 \\
\hline Aplicação de uréia (Urea aplication) & $0,6 \mathrm{~h}$ & 7,23 & 7,23 & 7,23 \\
\hline Arrendamento (Lease) & 0,5 ano & 15,16 & 15,16 & 15,16 \\
\hline Custo básico (Basic cost) & $\mathrm{kg} P V$ & 356,41 & 356,41 & 356,41 \\
\hline Sal comum (Salt) & $\mathrm{kg}$ & 2,85 & 3,23 & 2,80 \\
\hline Vermífugo(Vermifuge) & $\mathrm{L}$ & 5,46 & 6,18 & 5,35 \\
\hline Mão-de-obra (Labor) & $\mathrm{h}$ & 5,07 & 37,18 & 37,18 \\
\hline Suplemento (Supplement) & $\mathrm{kg}$ & & 167,0 & 105,19 \\
\hline Transporte (Transport) & $\mathrm{h}$ & & 37,03 & 37,03 \\
\hline Cocho (Trough) & $\mathrm{m}$ & & 4,94 & 4,94 \\
\hline Custo adicional (Additional cost) & $\mathrm{kgPV}$ & 13,38 & 255,55 & 192,49 \\
\hline Custo total (Total cost) & $\mathrm{kgPV}$ & 369,79 & 611,96 & 548,90 \\
\hline
\end{tabular}

\section{Resultados e Discussão}

Nas Tabelas 1 e 2, encontra-se a composição dos custos referentes aos sistemas alimentares estudados, respectivamente, nos experimentos 1 e 2 . Foi denominado 'custo básico' o valor correspondente à implantação e manutenção das pastagens, além do custo do arrendamento da terra. $\mathrm{O}$ valor denominado 'custo adicional' refere-se aos itens que sofrem variação na quantidade utilizada por hectare, em função de alterações na carga animal, e aos custos específicos dos sistemas nos quais os animais foram suplementados.

Com relação ao sistema de implantação das pastagens, o método de semeadura direta $(\mathrm{SD})$ realizado no experimento 2 proporcionou pequena redução nos custos quando comparado ao preparo convencional (PC) utilizado no experimento 1. Os valores correspondentes aos itens 'preparo do solo' e 'semeadura/ adubação' (Tabela 1) totalizaram um custo de $39,0 \mathrm{~kg}$ $\mathrm{PV}$, enquanto os itens 'herbicida', 'aplicação de herbicida' e 'semeadura/adubação' (Tabela 2) corresponderam a 33,9 kg PV. Este resultado está de acordo com os relatos de Perrachon \& Riani (2002), que analisaram o impacto econômico do sistema de semeadura direta de pastagens. Os autores concluíram que os custos de implantação não variam demasiadamente entre os sistemas PC e SD, porém, normalmente, verifica-se uma diferença em favor do segundo, que é relacionada ao menor gasto de combustível, menor demanda de mão-de-obra e menor necessidade de maquinários. Conseqüentemente, somam-se os conhecidos benefícios da semeadura com mínimo revolvimento de solo, como diminuição de erosão e degradação do solo, melhor aproveitamento de áreas marginais e encostas e aumento dos teores de matéria orgânica e de alguns nutrientes no solo a médio e longo prazos.

Os desembolsos referentes aos fertilizantes utilizados por ocasião da semeadura e da adubação nitrogenada de cobertura totalizaram valores semelhantes entre os experimentos analisados. Estes insumos representaram 72,9 e 68,5\% do 'custo básico' dos experimentos 1 e 2, respectivamente. Segundo Nehmi Filho (2002), a adubação de pastagens pode ser eficiente, desde que haja racionalidade econômica 
em sua utilização. A viabilidade econômica da aplicação deste tipo de insumo em maior ou menor escala dependerá da resposta das espécies utilizadas quanto à produção de forragem, a qual irá refletir em determinado potencial de produção animal (Santos et al., 2002). Estes autores, trabalhando com doses de $\mathrm{N}$ a partir de $100 \mathrm{~kg} / \mathrm{ha}$ em cobertura na mesma área dos experimentos 1 e 2, não encontraram diferença na produção de MS da pastagem de aveia e azevém. Na última década, o custo dos fertilizantes elevou-se em proporções muito superiores às variações ocorridas no preço pago ao produtor pelos produtos agropecuários. Portanto, torna-se fundamental que o administrador rural conheça o potencial de produção de cada espécie forrageira utilizada na propriedade considerando o histórico de utilização de insumos em anos anteriores e os valores de produção alcançados. Somente a partir da organização desses dados, é possível estabelecer, para cada área e espécie a serem trabalhadas, uma faixa ótima de utilização de fertilizantes fundamentada no componente econômico.

A introdução da técnica de suplementação dos animais, tanto na pastagem de verão (experimento 1) como na pastagem de inverno (experimento 2 ), modificou significativamente a composição dos custos dos sistemas de alimentação em relação ao uso exclusivo das pastagens. Os itens relacionados diretamente ao fornecimento de concentrados ('suplemento', 'transporte', 'mão-de-obra' e 'cochos') elevaram o 'custo básico' na média dos experimentos 1 e 2 em $89,7 \%$ nos sistemas que empregados o grão de milho e em $65,1 \%$ quando foram utilizados os subprodutos polpa cítrica ou casca de soja como suplementos. A alteração no 'custo total' dos sistemas com suplementação está intimamente ligada ao preço dos suplementos. Mesmo com os fertilizantes ainda aparecendo com elevada participação nos custos, o suplemento adquire o papel de componente mais relevante na determinação da economicidade desses sistemas, uma vez que constitui um insumo muito mais suscetível a variações bruscas de preço que os primeiros. Quando se analisa o custo referente ao uso da suplementação (custo adicional), é necessário saber o quanto a técnica pode elevar na produção animal. Constam, na Tabela 3, os resultados biológicos dos experimentos avaliados, que foram confrontados com o levantamento dos custos, para a apreciação da resposta econômica direta de cada sistema alimentar, exposta na Tabela 4.

Os resultados de produção animal por unidade de área foram semelhantes $(\mathrm{P}>0,05)$ entre os sistemas que utilizaram suplementação dentro de cada experimento e estes foram superiores aos respectivos sistemas de alimentação exclusivamente a pasto $(\mathrm{P}<0,05)$. A composição do GPA, no entanto, apresentou algumas particularidades que merecem ser comentadas. No experimento 1 , os suplementos promoveram incrementos similares tanto no GDM como na CAM, ao passo que, no experimento 2 , a casca de soja propiciou maior incremento no desempenho individual das novilhas, enquanto o grão de milho foi mais

Tabela 3 - Ganho de peso diário médio (GDM), carga animal média (CAM) e ganho de peso vivo por área (GPA) nos experimentos 1 e 2

Table 3 - Average daily gain (ADG), average stoking rate (ASR) and area live weight gain (LWG) on experiments 1 and 2

\begin{tabular}{lccc}
\hline Tratamento & GDM $(\mathrm{kg} / \mathrm{animal})$ & $\mathrm{CAM}(\mathrm{kg} / \mathrm{ha} \mathrm{de} \mathrm{PV})$ & GPA $(\mathrm{kg} / \mathrm{ha} \mathrm{de} \mathrm{PV})$ \\
Treatment & $A D G(\mathrm{~kg} /$ animal $)$ & ASR $(\mathrm{kg} / \mathrm{ha}$ of $L W)$ & $L W G(\mathrm{~kg} / \mathrm{ha}$ of $L W)$ \\
\hline
\end{tabular}

Experimento 1

Experiment 1

\begin{tabular}{|c|c|c|c|}
\hline $\begin{array}{l}\operatorname{PAST}_{1}\left(G R A S S_{1}\right) \\
\operatorname{PAST}_{1} / \mathrm{M}\left(G R A S S_{1} / C\right) \\
\operatorname{PAST}_{1} / \mathrm{P}\left(G R A S S_{1} / P\right)\end{array}$ & $\begin{array}{l}0,376 \mathrm{~b} \\
0,611 \mathrm{a} \\
0,615 \mathrm{a}\end{array}$ & $\begin{array}{l}1636,0 \mathrm{~b} \\
2065,5 \mathrm{a} \\
1987,6 \mathrm{a}\end{array}$ & $\begin{array}{l}324,8 \mathrm{~b} \\
554,9 \mathrm{a} \\
528,1 \mathrm{a}\end{array}$ \\
\hline \multicolumn{4}{|l|}{$\begin{array}{l}\text { Experimento } 2 \\
\text { Experiment } 2\end{array}$} \\
\hline $\begin{array}{l}\operatorname{PAST}_{2}(G R A S S 2) \\
\operatorname{PAST}_{2} / \mathrm{M}\left(G R A S S_{2} / C\right) \\
\operatorname{PAST}_{2} / \mathrm{C}\left(G R A S S_{2} / H\right)\end{array}$ & $\begin{array}{c}0,835 \mathrm{~b} \\
0,968 \mathrm{ab} \\
1,112 \mathrm{a}\end{array}$ & $\begin{array}{c}877,0 \mathrm{~b} \\
977,6 \mathrm{a} \\
923,7 \mathrm{ab}\end{array}$ & $\begin{array}{l}459,0 \mathrm{~b} \\
608,0 \mathrm{a} \\
602,8 \mathrm{a}\end{array}$ \\
\hline
\end{tabular}

Médias seguidas de letras distintas, na coluna, diferem estatisticamente $(\mathrm{P}<0,05)$.

Means followed by distinct letters, in a colunm, are different statistically $(P<.05)$.

R. Bras. Zootec., v.33, n.6, p.2359-2368, 2004 (Supl. 3) 
Tabela 4 - Custo total (CT), receita bruta (RB) e margem bruta (MB) por hectare e retorno financeiro direto (RFD) por tratamento nos experimentos 1 e 2. Valores expressos em kg PV de novilha

Table 4 - Total cost (TC), gross income (GI), gross margin (GM) per hectare, and direct financier return (RFD) per treatment, on experiments 1 and 2. Values express in $\mathrm{kg} \mathrm{LW}$ of heifer

\begin{tabular}{|c|c|c|c|c|}
\hline Tratamento & $\mathrm{CT}$ & $\mathrm{RB}$ & $\mathrm{MB}$ & RFD \\
\hline Treatment & $T C$ & GI & $G M$ & $D F R$ \\
\hline \multicolumn{5}{|l|}{ Experiment 1} \\
\hline \multicolumn{5}{|l|}{ Experiment 1} \\
\hline $\operatorname{PAST}_{1}\left(G R A S S_{1}\right)$ & 314,5 & 324,8 & 10,3 & 1,03 \\
\hline $\mathrm{PAST}_{1} / \mathrm{M}\left(G R A S S_{1} / C\right)$ & 627,9 & 554,9 & $-73,0$ & 0,88 \\
\hline $\mathrm{PAST}_{1}^{1} / \mathrm{P}\left(\right.$ GRASS $\left._{1} / P\right)$ & 536,0 & 528,1 & $-7,9$ & 0,99 \\
\hline \multirow{2}{*}{\multicolumn{5}{|c|}{$\begin{array}{l}\text { Experimento } 2 \\
\text { Experimento } 2\end{array}$}} \\
\hline & & & & \\
\hline $\operatorname{PAST}_{2}\left(G R A S S_{2}\right)$ & 369,8 & 459,0 & 89,2 & 1,24 \\
\hline $\mathrm{PAST}_{2} / \mathrm{M}\left(G R A S S_{2} / C\right)$ & 611,9 & 608,0 & $-3,9$ & 0,99 \\
\hline $\mathrm{PAST}_{2} / \mathrm{C}\left(G R A S S_{2} / H\right)$ & 548,9 & 602,8 & 53,9 & 1,10 \\
\hline
\end{tabular}

eficiente no aumento da capacidade de suporte da pastagem, todos em relação aos respectivos tratamentos em que não se utilizou a suplementação. De qualquer forma, pode-se inferir que houve compensação entre os incrementos obtidos em cada parâmetro, o que resultou em valores de GPA similares.

$\mathrm{O}$ aumento na produção de carne por hectare verificado em todos os sistemas nos quais se utilizou a suplementação energética superou o investimento adicional somente quando se trabalhou com a casca de soja como suplemento no experimento 2. Na pastagem estival (experimento 1), a suplementação com grão de milho apresentou considerável prejuízo financeiro, enquanto a utilização de polpa cítrica no verão e do grão de milho no inverno praticamente cobriram o 'custo adicional', sem excedente de margem bruta. Neste último caso, no sistema de produção, poder-se-ia contar apenas com os possíveis benefícios indiretos da suplementação, como, por exemplo, o menor investimento em áreas de pastagem cultivada e o melhor desenvolvimento das fêmeas, em peso e condição corporal, aos 12 meses de idade. Para potencializar economicamente o incremento em produção animal proporcionado pela suplementação, é necessário trabalhar com suplementos de baixo custo (Rocha et al., 2003), pois a grande vantagem em investir na suplementação, em relação ao uso exclusivo da pastagem, está no baixo risco ligado ao fornecimento do suplemento, uma vez que a quantida- de oferecida não depende de condições climáticas. Rocha et al. (2001) apresentam como uma das principais vantagens da suplementação a aceleração no ganho de peso dos animais, antecipando a liberação da área para outras categorias ou para implantação de culturas subsequientes.

Ainda com relação à análise da resposta financeira direta dos sistemas estudados, salienta-se que os resultados apresentados foram calculados com base na atualização dos preços dos insumos e do produto final em janeiro de 2003. Da época real de aquisição desses insumos, janeiro de 2001, até a data da atualização dos preços, todos sofreram acréscimos significativos, sendo o aumento no preço dos suplementos de maior repercussão no custo total. Em apenas dois anos, verificou-se aumentos de 76, 53 e $100 \%$ nos valores pagos, respectivamente, pelo quilo de milho em grão, de polpa cítrica e de casca de soja, enquanto o preço pago pelo kg PV de novilha elevou em apenas $16 \%$, o que confirma que a simples variação no preço do suplemento, como, por exemplo, sua redução emd relação aos valores praticados em 2001, provocaria total alteração na análise econômica anterior, mesmo considerando situação de seteris paribus para os demais componentes do custo. Nesta hipótese, a margem bruta seria bastante favorável aos sistemas em que se fez uso da suplementação, em relação aos valores obtidos para este parâmetro nos sistemas de alimentação exclusivamente a pasto.

A análise econômica é importante para o produtor na tomada de decisões, pois permite a avaliação do impacto econômico de novas tecnologias no sistema com a utilização dos recursos disponíveis - terra, capital e mão-de-obra (Riesco \& Seré, 1986). Considerando-se as fêmeas em recria, no entanto, existem outros aspectos a serem considerados que não somente o resultado financeiro das operações, quando da avaliação da eficiência de práticas que visam a intensificação do sistema produtivo em geral. Constam na Tabela 5 o peso das novilhas ao completarem um ano de idade, dos experimentos 1 e 2, e as estimativas de GDM necessário para redução da idade ao primeiro acasalamento de 36 meses para 24, 18 ou 14 meses.

As estimativas de GDM para o acasalamento das novilhas em diferentes idades evidenciam que o peso vivo destes animais aos 12 meses inviabilizou biologicamente o ingresso destes animais no sistema ' 14 meses'. Para o acasalamento aos 18 meses de idade, somente as novilhas que receberam suplementação em pelo menos um dos experimentos poderiam ser 
manejadas em pastagem nativa até o período destinado ao primeiro serviço. Todos os sistemas alimentares estudados, entretanto, permitiram a preconização do acasalamento das novilhas aos dois anos de idade. A partir desses resultados, foi realizada uma avaliação do impacto proporcionado pela redução da idade ao primeiro acasalamento de 36 (sistema 'tradicional') para 24 meses de idade (sistema 'dois anos'). Para esta análise, utilizou-se uma adaptação do modelo de estrutura do rebanho de corte proposto por Beretta et al. (2001) (Tabela 6).

Por intermédio do modelo de composição percentual do rebanho para os animais envolvidos com o ciclo reprodutivo é possível fazer uma análise de como o desmame aos 60-90 dias de idade e a intensificação do sistema de recria, práticas realizadas com as novilhas dos experimentos 1 e 2 , podem afetar positivamente a produtividade do sistema criatório como um todo. No caso do sistema 'tradicional' com $\mathrm{TN}$ de $50 \%$ para cada 100 vacas prenhas no rebanho, existiriam 197 fêmeas improdutivas, entre vacas vazias e novilhas para reposição, estas últimas com idade entre seis meses e três anos. A redução da IA para dois anos de idade mantendo-se a mesma taxa de natalidade reduziria este número em $23 \%$, passando a existir 151 fêmeas para cada 100 vacas

Tabela 5 - Peso vivo médio de novilhas de corte aos 12 meses de idade $\left(\mathrm{PV}_{12}\right)$ e estimativas de GDM para acasalamento aos 14, 18 ou 24 meses de idade

Table 5 - Average live weight of beef heifers at 12 months of age $\left(L W_{12}\right)$ and ADG estimates of mating at 14,18 or 24 months of age

\begin{tabular}{|c|c|c|c|c|}
\hline \multirow[t]{2}{*}{$\begin{array}{l}\text { Tratamento } \\
\text { Treatment }\end{array}$} & $\begin{array}{l}\mathrm{PV}_{12}(\mathrm{~kg}) \\
L W_{12}(k g)\end{array}$ & $\begin{array}{c}\mathrm{GDM}_{12-14}(\mathrm{~kg}) \\
A D G_{12-14}(\mathrm{~kg})\end{array}$ & $\begin{array}{c}\mathrm{GDM}_{12-18}(\mathrm{~kg}) \\
A D G_{12-18}(\mathrm{~kg})\end{array}$ & $\begin{array}{c}\mathrm{GDM}_{12-24}(\mathrm{~kg}) \\
A D G_{12-24}(\mathrm{~kg})\end{array}$ \\
\hline & $\begin{array}{l}\text { Observado } \\
\text { Observed }\end{array}$ & \multicolumn{3}{|c|}{ 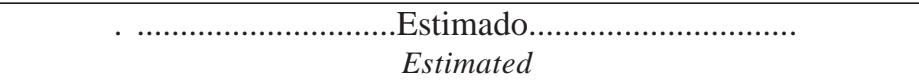 } \\
\hline SUPL 1 e $2 S U P P L 1$ e 2 & $202,7 \mathrm{a}$ & 1,756 & 0,374 & 0,175 \\
\hline SUPL 1SUPPL 1 & $178,3 \mathrm{ab}$ & 2,368 & 0,504 & 0,236 \\
\hline SUPL 2SUPPL 2 & $190,0 \mathrm{a}$ & 2,075 & 0,441 & 0,206 \\
\hline N-SUPLN-SUPPL & $132,0 \mathrm{~b}$ & 3,525 & 0,750 & 0,351 \\
\hline
\end{tabular}

Médias seguidas de letras distintas, na coluna, diferem estatisticamente $(P<0,05)$.

Means followed by distinct letters, in a column, are different statisticaly $(P<.05)$.

SUPL 1 e 2 - novilhas suplementadas nos experimentos 1 e 2 (SUPPL 1 and 2 - heifers supplemented in the experiments 1 and 2).

SUPL 1 - novilhas suplementadas somente no experimento1 (SUPPL 1 - heifers supplemented only in the experiment 1).

SUPL 2 - novilhas suplementadas somente no experimento 2 (SUPPL 2 - heifers supplemented only in the experiment 2).

N-SUPL - novilhas mantidas exclusivamente a pasto; N-SUPPL (heifers maintained exclusively at grassland).

Tabela 6 - Estrutura do rebanho em sistemas de cria, conforme a idade das novilhas ao primeiro acasalamento (IA) e a taxa de natalidade (TN) do rebanho de cria adulto*

Table 6 - Herd structure in breeding systems with different heifer first mating (MA) and calving rate (CR) of the mature herd*

\begin{tabular}{|c|c|c|c|c|}
\hline & \multicolumn{4}{|c|}{$\begin{array}{c}\text { Taxa de natalidade }(\%) \\
\text { Breeding rate }(\%)\end{array}$} \\
\hline & 50 & 60 & 70 & 80 \\
\hline \multicolumn{5}{|l|}{ Sistema tradicional $* *$ (Traditional system $* *$ ) } \\
\hline Vacas prenhas (\%) (Pregnant breeding cows, \%) & 33 & 37 & 43 & 56 \\
\hline Vacas vazias (\%) (Non pregnant cows, \%) & 18 & 8 & 1 & 0 \\
\hline Novilhas (\%) (Heifers, \%) & 47 & 53 & 54 & 42 \\
\hline Touros (\%) (Bulls, \%) & 2 & 2 & 2 & 2 \\
\hline \multicolumn{5}{|l|}{ Sistema dois anos*** (Two years system $* * *)$} \\
\hline Vacas prenhas (\%) (Pregnant breeding cows, \%) & 39 & 45 & 52 & 64 \\
\hline Vacas vazias $(\%)$ (Non pregnant cows, \%) & 21 & 9 & 0 & 0 \\
\hline Novilhas (\%) (Heifers, \%) & 38 & 44 & 46 & 33 \\
\hline Touros (\%) (Bulls, \%) & 2 & 2 & 2 & 3 \\
\hline
\end{tabular}

* Adaptado de Beretta et al. (2001) (Adapted from Beretta et al., 2001).

** $\quad I A=$ três anos de idade $(M A=$ three years old $)$.

$* * * I A=$ dois anos de idade $(M A=$ two years old $)$.

R. Bras. Zootec., v.33, n.6, p.2359-2368, 2004 (Supl. 3) 
prenhas. Admitindo-se a potencialidade da técnica do desmame aos 60-90 dias para aumentar a TN do rebanho para $80 \%$, o sistema 'tradicional' dependeria da manutenção de 75 fêmeas improdutivas/100 vacas prenhas, o que representa uma redução de $62 \% \mathrm{em}$ relação ao valor inicial de 197 fêmeas fora de produção no sistema-cria. A realização das duas técnicas conjuntamente, o desmame precoce dos bezerros e a redução na IA para dois anos, representaria a alteração mais significativa na estrutura do rebanho, pois existiriam apenas 52 fêmeas improdutivas para cada 100 vacas prenhas no rebanho, valor $74 \%$ inferior ao estimado para o sistema 'tradicional'. As duas últimas hipóteses de sistema criatório ainda apresentariam como vantagens o descarte de todas as vacas vazias do rebanho, o que normalmente traz grande impacto econômico para o sistema. O aumento da taxa de natalidade para $70-80 \%$ pode gerar um incremento da margem bruta entre 35 e $60 \%$ dependendo da fase de comercialização dos animais e da taxa de natalidade alcançada (Grawunder, 1988). Por fim, a eliminação permanente da categoria 'novilhas 2-3 anos' e da categoria 'vacas vazias' a partir de abril propiciariam a liberação de áreas a serem utilizadas por categorias mais produtivas do rebanho ou com outra finalidade de exploração.

A adoção de tecnologias que visem a intensificação da produção e o avanço dos índices de produtividade implica, certamente, num aumento dos custos de produção. Entretanto, a redução da idade ao primeiro acasalamento de três para dois anos em sistemas com taxa de natalidade de $80 \%$ requer um investimento em pastagem cultivada de apenas $6 \%$ da superfície pastoril total (Pötter et al., 1998). O acasalamento das novilhas aos 14 meses é uma alternativa que depende de maior disponibilidade de capital para investimento e de maior capacitação da mão-de-obra utilizada. Entre as razões para a realização do sistema 'dois anos', Short et al. (1994) ressaltam o fato de que existem regiões onde a quantidade e/ou qualidade da forragem disponível constitui fator limitante em determinada época do ano. Este aspecto pode ser representado pelos meses de outono no RS, que podem comprometer até mesmo os resultados de sistemas intensivos de alimentação utilizados em período anterior ou subseqüente à estação outonal. Alternativas para sanar este déficit alimentar são constantemente apresentadas pelos pesquisadores (Rocha \& Lobato, 2002; Alves Filho et al., 1999; Lobato, 1997) no afã de viabilizar a implementação de sistemas cada vez mais intensivos. Mielitz Netto (1994), no entanto, salienta que, no Rio Grande do Sul, onde a exploração da pecuária de corte é realizada há muito tempo e em moldes extensivos, a mudança do perfil tradicional do produtor é mais lenta que nas novas regiões de exploração da atividade. Isto reforça a motivação para que a pesquisa científica e principalmente o serviço de extensão rural e assessoria técnica trabalhem em prol da consolidação da redução da idade ao primeiro acasalamento das novilhas de 36 para 24 meses de idade, concomitantemente à difusão e assessoramento de técnicas que visem aumentos da taxa de natalidade dos rebanhos. Estes podem ser os pontos-chave da intensificação do sistema de produção de gado de corte com resultados econômicos satisfatórios.

O impacto causado pelo desmame aos 60-90 dias sobre a as taxas de repetição de prenhez e natalidade é um benefício direto desta prática, independentemente do manejo alimentar necessário às novilhas a partir do desmame. O sistema de recria, por sua vez, irá determinar o grau de intensificação possível para o sistema de acasalamento das fêmeas. No caso dos experimentos analisados neste estudo, a introdução da técnica da suplementação dos animais não seria necessária para oportunizar o acasalamento aos 24 meses. Sua utilização, todavia, deve ser considerada como ferramenta que agrega grande segurança de resultados para a manutenção do sistema, principalmente em situações desfavoráveis de utilização das pastagens.

\section{Conclusões}

A suplementação energética de novilhas em pastagens de gramíneas anuais aumenta a produção animal, o custo total e a receita bruta por hectare. A margem bruta é dependente da variação no preço do suplemento.

Os subprodutos polpa cítrica e casca de soja proporcionam incrementos no ganho de peso por área semelhantes aos obtidos com o grão de milho como suplemento energético e são mais eficientes do ponto de vista econômico.

O aumento da taxa de natalidade de 50 para $80 \%$ apresenta maior impacto sobre o número de fêmeas improdutivas no rebanho que a redução de três para dois anos na idade ao primeiro acasalamento das novilhas. O resultado mais expressivo é verificado quando ambas as práticas são realizadas simultaneamente.

R. Bras. Zootec., v.33, n.6, p.2359-2368, 2004 (Supl. 3) 


\section{Literatura Citada}

ALVES FILHO, D.C.; BERNARDES, R.A.L.C.; BRONDANI, I.L. Suplementação de verão/outono. In: RESTLE, J. (Ed.). Confinamento, pastagens e suplementação para produção de bovinos de corte. 1.ed. Santa Maria, p.39-61, 1999.

ANUALPEC. Anuário estatístico da pecuária brasileira. São Paulo: Ed. Argos Comunicação, 2002. 400p.

BERETTA, V.; LOBATO, J.F.P.; MIELITZ NETTO, C.G. Produtividade e eficiência biológica de sistemas pecuários de cria diferindo na idade das novilhas ao primeiro parto e da taxa de natalidade do rebanho no Rio Grande do Sul. Revista Brasileira de Zootecnia, v.30, n.4, p.1278-1286, 2001.

CACHAPUZ, J.M. da S. O panorama setorial da bovinocultura de corte gaúcha no processo de integração do Mercosul. 2.ed. Porto Alegre: Emater, 1995. 68p. (Realidade Rural, 7).

GRAWUNDER, A.F. Pecuária de corte: um avanço tecnológico apreciável. Rev. Lav. Arroz., Porto Alegre, v.41, n.378, p.18-26, 1988.

HODGSON, J. Grazing Management: Science into pratice. London: Longman Scientific \& Techinical, 1990.203p.

LOBATO, J.F.P. Sistemas intensivos de produção de carne bovina: 1. cria. In: SIMPÓSIO SOBRE PECUÁRIA DE CORTE, 4, 1997, Piracicaba. Anais... Piracicaba: FEALQESALQ, 1997. p.161-204.

MIELITZ NETTO, C.G.A. Modernização e diferenciação na bovinocultura de corte brasileira. Campinas: Universidade Estadual de Campinas, 224p. Tese (Doutorado em Economia) - Instituto de Economia, Universidade Estadual de Campinas, 1994

MIELITZ NETTO, C.G.A. Análise das mudanças de alguns coeficientes técnicos na criação de bovinos de corte no Rio Grande do Sul. Porto Alegre: Universidade Federal do Rio Grande do Sul, 62p. Dissertação (Mestrado em Economia Rural) - Universidade Federal do Rio Grande do Sul, 1979.

MORENO, J.A. Clima do Rio Grande do Sul. Porto Alegre: Secretaria da Agricultura, 1961. 41p.

MOTT, G.O.; LUCAS, H.L. The design conduct and interpretation of grazing trials on cultivated and improved pastures. In: INTERNATIONAL GRASSLAND CONGRESS, 6., 1952. Proceedings... Pensylvania: State College Press, 1952. p.1380-1395.

NEHMI FILHO, V.A. A economia regula a adubação de pastagens. São Paulo: Argos Comunicação, ANUALPEC, 2002. p.16-21.

PERRACHON, J.; RIANI, V. Siembra directa y su impacto económico. Revista del plan agropecuario, 2002, p.39-42.

PÖTTER, L.; LOBATO, J.F.P.; MIELITZ NETTO, C.G.A. Análises econômicas de modelos de produção com novilhas de corte primíparas aos dois anos, três e quatro anos de idade. Revista Brasileira de Zootecnia, v.29, n.3, p.861-870, 2000.
PÖTTER, L.; LOBATO, J.F.P.; MIELITZ NETTO, C.G.A. Produtividade de um modelo de produção de para novilhas de corte primíparas aos dois, três e quatro anos de idade. Revista Brasileira de Zootecnia, v.27, n.3, p.613-619, 1998.

PÖTTER, L. Produtividade e análise econômica de um modelo de produção de para novilhas de corte primíparas aos dois, três e quatro anos de idade. Porto Alegre: Universidade Federal do Rio Grande do Sul, 1997. 148p. Dissertação (Mestrado em Zootecnia) - Universidade Federal do Rio Grande do Sul, 1997.

RIESCO, A.; SERÉ, C. Análisis económico de resultados de las pruebas de pastoreo. In: LASCANO, C.; PIZARRO, E. (Eds.). Evaluación de pasturas con animales. Alternativas metodológicas. Cali: CIAT, 1986. p.201-232.

ROCHA, M.G.; RESTLE, J.; PILAU, A. et al. Produção animal e retorno econômico da suplementação em pastagem de aveia e azevém. Ciência Rural, v.33, n.3, p.85-93, 2003.

ROCHA, M.G.; LOBATO, J.F.P. Sistemas de alimentação pósdesmama de novilhas de corte para acasalamento com 14/15 meses de idade. Revista Brasileira de Zootecnia, v. 31, n.4, p.1814-1822, 2002.

ROCHA, M.G.; RESTLE, J.; SANTOS, D.T. et al. Produção animal em sistemas intensivos de utilização da pastagem de aveia mais azevém. In: REUNIÃO ANUAL DA SOCIEDADE BRASILEIRA DE ZOOTECNIA, 38., 2001, Piracicaba. Anais... Piracicaba: Sociedade Brasileira de Zootecnia, 2001. p.191.

SALLES, P.A.; AMESTOY, A.C.; BERNARDES, R.M. et al. Abater o novilho aos dois anos aumenta a receita líquida da pecuária. Coletânea das pesquisas... Bagé: EMBRAPA, 1987. p.419-433.

SALOMONI, E. Sistemas de produção em bovinos de corte. Coletânea das pesquisas... Bagé: EMBRAPA, 1987. p.419-433.

SANTOS, D.T.; ROCHA, M.G.; QUADROS, F.L.F. et al. Dinâmica de gramíneas anuais sob pastejo e doses de nitrogênio. In: REUNIÓN DE GRUPO TÉCNICO EM FORRAJERAS DEL CONO SUR, 19., 2002, Mercedes. Memorias... Mercedes: INTA, 2002. p.177-178.

SHORT, R.E.; STAIGMILLER, R.B.; BELLOWS, R.A. Breeding heifers at one year of age: biological and economic considerations. In: FIELDS, M.J.; SAND, R.S. (Eds.) Factors affecting calf crop. Gainesville: CRC Press, 1994. p.55-68.

ZERVOUDAKIS, J.T.; PAULINO, M.F.; DETMANN, E. et al. Desempenho de novilhas mestiças e parâmetros ruminais em novilhos, suplementados durante o período das águas. Revista Brasileira de Zootecnia, v.31, n.2, p.1050-1058, 2002 (suplemento). 